\title{
Study of Compression Molding of GFRP using Grey Relational Analysis
}

\author{
M.Santhanakumar ${ }^{*}$ and R.Adalarasan ${ }^{2}$ \\ ${ }^{1}$ Research Scholar, Anna University, Chennai-600025, India \\ 2Department of Mechanical Engineering, Saveetha Engineering College, Chennai-602105, India \\ *Email: msanthanakumar@gmail.com
}

\begin{abstract}
Compression moulding is an economical process for processing thermosetting polymers hence finding numerous applications in industries. The moulding parameters like the pressure, temperature and curing time play an important role in influencing the quality characteristics of the manufactured component. The present work is intended to produce fibre glass reinforced epoxy stiffeners using the process of compression moulding for various combinations of input parameters. The input parameters were varied at two levels and a L8 orthogonal array was chosen to perform the trials. Grey relational analysis (GRA) was applied for optimizing the process parameters and ANOVA was performed to identify the contribution of various process parameters.
\end{abstract}

Keywords: Compression moulding; Optimization; Grey relational analysis; GFRP.

\section{INTRODUCTION}

The Glass fibre reinforced plastics (GFRP) are known for their better properties and wide industrial applications. Compression moulding is an important polymer processing operation in the plastic industries in forming plastic parts of complex shapes with good precision and accuracy. Among the various polymers reinforced with glass fibre, the epoxy matrix was found to be more suitable as the interface bond was found to be good [1]. However moisture absorption has a huge impact on degrading the tensile strength of these composites [2]. The bonding interfaces play an influential role in affecting the mechanical properties of the fibre reinforced plastics and this bond between the matrix and the reinforcement was identified as a function of the temperature, pressure and curing time in compression moulding [3]. The volume fraction of fibre in compression moulded composites affect the quality of the surface and its properties [4]. It was also found that the mechanical properties of polymer composites were improved by reduced the moulding pressure and time while an increase in temperature was found to reduce their strength [5]. While modelling using statistical processes it was observed that the curing time was the prime factor influencing the properties [6].

The multi response optimization problems can be solved by using the grey relational analysis (GRA), principal component analysis (PCA) and data envelopment analysis (DEA) [7]. Though more interest was shown in using the response surface methodology (RSM), artificial neural network (ANN) and genetic algorithm (GA) for optimization these techniques have their own limitations $[8,9]$. TOPSIS is a ranking technique which is easy to understand and implement. It is a multi-attribute decision making (MADM) technique applied to solve problems with a finite number of options [10]. From the literature review it was found that multi response optimization performed in the area of compression moulding of GFRP is scarce. Hence the present work discloses the application of GRA to predict the optimal setting of parameters in compression moulding.

\section{MATERIAL AND EXPERIMENTAL METHOD}

The thermosetting polymer epoxy is used as the matrix material and E-glass fibre is used as the reinforcement (20\% weight fraction). The epoxy based composite stiffeners were prepared by the process of compression moulding. The various parameters selected for the study include the temperature (T), compression pressure $(\mathrm{P})$ and curing time (CT). Two levels were chosen for the various parameters and a $\mathrm{L} 8$ orthogonal array was used to conduct the experiments for different combinations of the parameters. The responses observed include the Tensile strength (TS) 
and bending strength (BS). The responses observed during the nine trials are shown in Table 1.

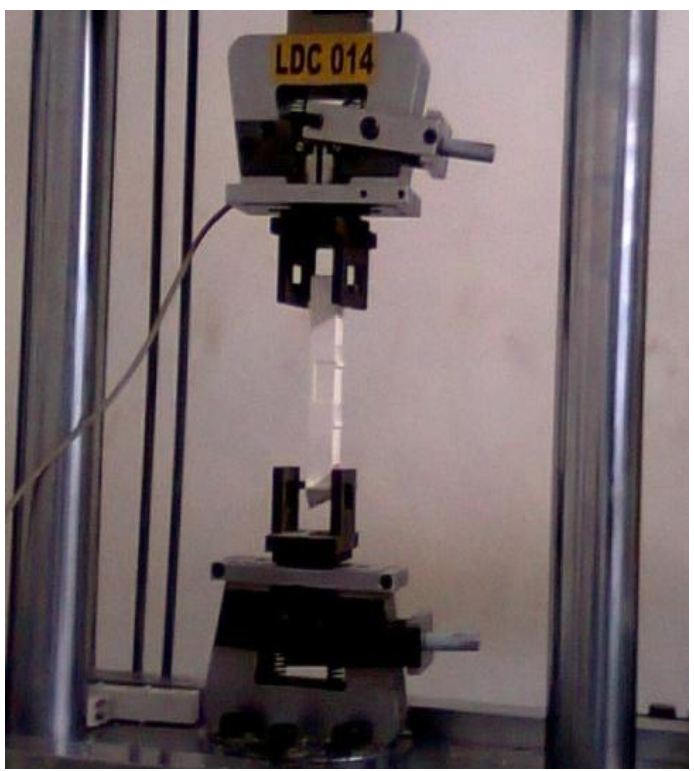

Fig. 1 Tension testing of GFRP stiffeners

Table 1. Responses observed during the different trials

\begin{tabular}{|c|c|c|c|c|c|}
\hline \multirow{2}{*}{ Trial } & \multicolumn{3}{|c|}{ Parameters } & \multicolumn{2}{c|}{ Responses } \\
\cline { 2 - 6 } & $\begin{array}{c}\mathrm{T} \\
\left({ }^{0} \mathrm{C}\right)\end{array}$ & $\begin{array}{c}\mathrm{P} \\
(\mathrm{MPa})\end{array}$ & $\begin{array}{c}\mathrm{CT} \\
(\mathrm{min})\end{array}$ & $\begin{array}{c}\text { TS } \\
(\mathrm{MPa})\end{array}$ & $\begin{array}{c}\mathrm{BS} \\
(\mathrm{MPa})\end{array}$ \\
\hline 1 & 120 & 50 & 3 & 61.56 & 76.88 \\
\hline 2 & 120 & 50 & 4 & 66.52 & 67.68 \\
\hline 3 & 130 & 60 & 3 & 86.2 & 88.12 \\
\hline 4 & 130 & 60 & 4 & 84.12 & 74.92 \\
\hline 5 & 120 & 60 & 3 & 78.08 & 89.48 \\
\hline 6 & 120 & 60 & 4 & 72.4 & 79.84 \\
\hline 7 & 130 & 50 & 3 & 80.56 & 73.4 \\
\hline 8 & 130 & 50 & 4 & 84.12 & 72.48 \\
\hline
\end{tabular}

\section{MULTI RESPONSE OPTIMIZATION USING GREY RELATIONAL ANALYSIS (GRA)}

The algorithm for GRA is disclosed below.

Step 1: The $S / N$ ratios for the responses were calculated using the Eq. 1.

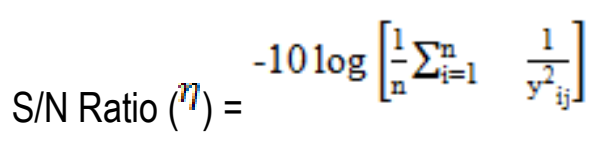

Where $n=$ number of replications; $k=$ number of observations; $y i j=$ observed response value; $i=1,2,3 \ldots$ $n$ and $\mathrm{j}=1,2, \ldots \mathrm{k}$.

Step 2: Calculate the normalised $\mathrm{S} / \mathrm{N}$ ratio using the Eq. 2.

$$
Z_{i j}=\frac{y_{i j}-\min \left(y_{i j,}, i=1,2_{a m m} n\right)}{\max \left(y_{i j}, i=1,2, \ldots m, n\right)-\min \left(y_{i j}, i=1,2, m, n\right)}
$$

Step 3: Calculate the grey relational coefficient (GRC) to express the relationship between the best and the actual normalized experimental results using the Eq. 3.

$$
\mathrm{Y}(\mathrm{yo}(\mathrm{k}), \mathrm{yi}(\mathrm{k}))=\frac{\Delta \min +\xi_{\Delta \max }}{\Delta_{o j}(k)+\xi_{\Delta \max }}
$$

Step 4: Calculate the Grey relational grade (GRG) by taking the average of the GRC of the corresponding responses.

Step 5: Calculate the main effect of the factors on the GRG for each level. The best level of each control factor is selected as the one with higher value of GRG.

Step 6: Perform ANOVA to identify the contribution of parameters.

\section{RESULTS AND DISCUSSION}

Implementation of the methodology of GRA.

The technique of GRA was implemented starting with the calculations of $S / N$ ratio, normalized $S / N$ ratio as a part of data pre-processing. The calculated values of GRC and GRG were shown in Table 2. The GRG values offer an overall representation for the responses. The GRG values plotted for the various trials were indicated in the Fig. 2. 
Table 2. Normalized S/N ratio and GRG values

\begin{tabular}{|c|c|c|c|c|c|c|c|}
\hline \multirow{2}{*}{ Trial } & \multicolumn{2}{|c|}{ S/N ratio } & \multicolumn{2}{c|}{$\begin{array}{c}\text { Normalized } \\
\text { S/N ratio }\end{array}$} & \multicolumn{2}{c|}{ GRC } & \multirow{2}{*}{ GRG } \\
\cline { 2 - 7 } & TS & BS & TS & BS & TS & BS & \\
\hline 1 & 35.785 & 37.7162 & 0 & 0.4564 & 0.333 & 0.479 & 0.406 \\
\hline 2 & 36.4590 & 36.6092 & 0.2301 & 0 & 0.394 & 0.333 & 0.364 \\
\hline 3 & 38.7101 & 38.9014 & 1 & 0.9451 & 1.000 & 0.901 & 0.951 \\
\hline 4 & 38.4979 & 37.4919 & 0.9274 & 0.3639 & 0.873 & 0.440 & 0.657 \\
\hline 5 & 37.8508 & 39.0345 & 0.7061 & 1 & 0.630 & 1.000 & 0.815 \\
\hline 6 & 37.1947 & 38.0444 & 0.4817 & 0.5917 & 0.491 & 0.551 & 0.521 \\
\hline 7 & 38.1223 & 37.3139 & 0.7990 & 0.2905 & 0.713 & 0.413 & 0.563 \\
\hline 8 & 38.4979 & 37.2043 & 0.9274 & 0.2453 & 0.873 & 0.399 & 0.636 \\
\hline
\end{tabular}

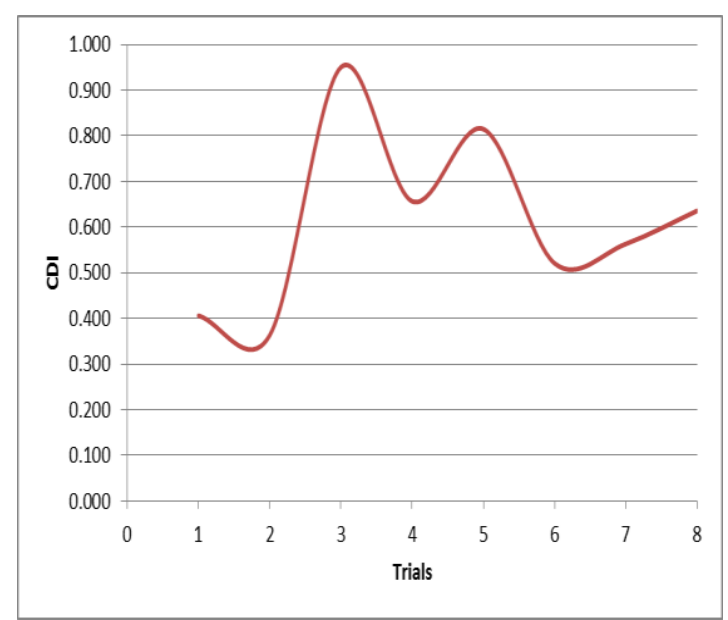

Fig. 2 Plot of GRG values for various trials

The main effect of the parameters on the GRG was calculated for each level and shown in Table 3. The best level of each factor is identified as the one with the maximum value of GRG. The optimal parameter level was found out as T2P2CT1. The results of ANOVA on GRG are shown in Table 4. It can be used to identify the contribution of the various process parameters in influencing the responses. The contribution chart is shown in Fig. 3.

Table 3. Main effect of parameters on GRG

\begin{tabular}{|c|r|r|r|}
\hline Parameters & \multicolumn{1}{|c|}{ Level 1 } & \multicolumn{1}{c|}{ Level 2 } & Max-Min \\
\hline $\mathrm{T}$ & 0.5263 & $\mathbf{0 . 7 0 1 6}$ & 0.1752 \\
\hline $\mathrm{P}$ & 0.4922 & $\mathbf{0 . 7 3 5 7}$ & 0.2434 \\
\hline $\mathrm{CT}$ & $\mathbf{0 . 6 8 3 7}$ & 0.5442 & 0.1395 \\
\hline
\end{tabular}

Table 4. Results of ANOVA on GRG

\begin{tabular}{|c|c|c|c|c|c|}
\hline $\begin{array}{c}\text { Source } \\
\text { of } \\
\text { variance }\end{array}$ & $\begin{array}{c}\text { Sum of } \\
\text { squares }\end{array}$ & $\begin{array}{c}\text { Degrees } \\
\text { of } \\
\text { freedom }\end{array}$ & $\begin{array}{c}\text { Mean } \\
\text { sum of } \\
\text { square }\end{array}$ & F-ratio & $\begin{array}{c}\% \\
\text { Contribution }\end{array}$ \\
\hline $\mathrm{T}$ & 0.0614 & 2 & 0.0307 & 1.1344 & 22.4952 \\
\hline $\mathrm{P}$ & 0.1185 & 2 & 0.0592 & 2.1894 & 43.4167 \\
\hline $\mathrm{CT}$ & 0.0389 & 2 & 0.0194 & 0.719 & 14.2576 \\
\hline Error & 0.0541 & 2 & 0.0270 & & 19.8304 \\
\hline Total & 0.2730 & 8 & & & 100 \\
\hline
\end{tabular}




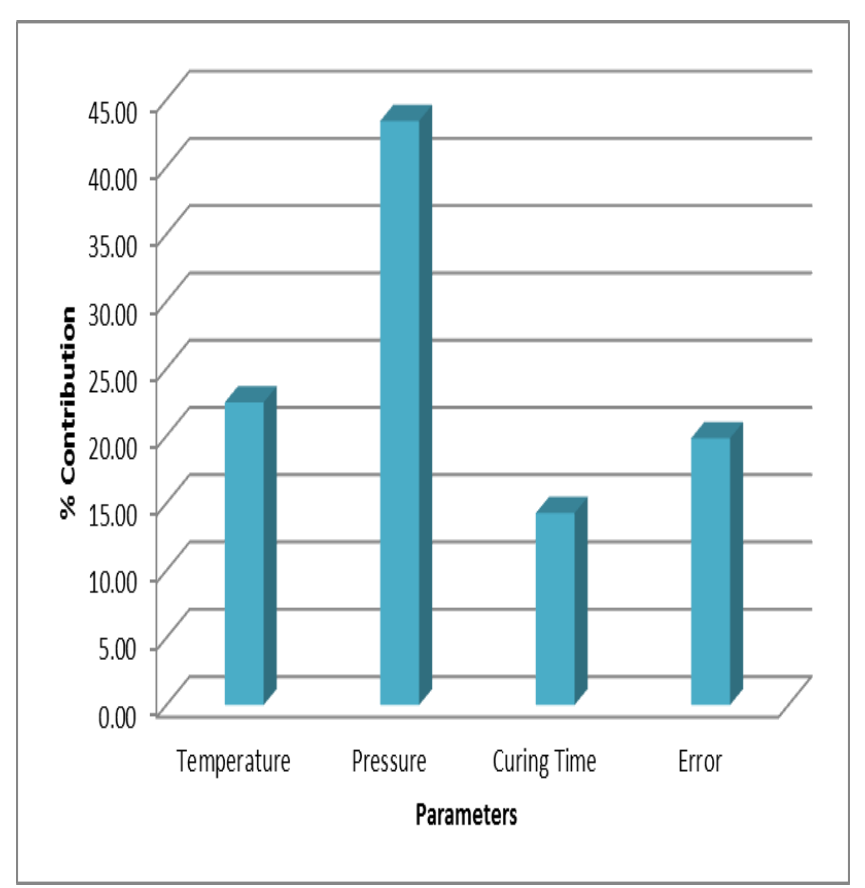

Fig. 3 Contribution chart

\section{v. CONCLUSION}

This paper is an informative report on the compression moulding of E-glass fiber reinforced Epoxy composites. The following conclusions were drawn.

- The effective ranking technique of GRA was employed to perform the multi response optimization of E-glass reinforced Epoxy matrix. The optimal setting of input parameters were identified as temperature: temperature: $1300 \mathrm{C}$, pressure: $60 \mathrm{MPa}$ and curing time: $3 \mathrm{~min}$.

- From the ANOVA results compression pressure was identified as the prime factor influencing the responses with a contribution of $43.41 \%$ followed by the temperature and curing time.

\section{References}

1. M.M. Thwea, Kin Liaob, Durability of bamboo-glass fiber reinforced polymer matrix hybrid composites, Compos Sci Technol. 63 (2003) 375-387.

2. T.H. Almusallam, Y.A. Al-Salloum, S.H. Alsayed, S. ElGamal, M. Aqel, Tensile properties degradation of glass fiber-reinforced polymer bars embedded in concrete under severe laboratory and field environmental conditions, J Compos Mater. 47(4) (2013) 393-407.

3. A.T. DiBenedetto, Tailoring of interfaces in glass fiber reinforced polymer composites: a review, Materials Science and Engineering. 302(1) (2001) 74-82.

4. Jae-Seung Cheon, Yong-Taek Im, Determination of Short Glass-Fiber Volume Fractions in Compression Molded Thermoset Composites-Experimental, J Compos Mater. 33(6) (1999) 525-546.

5. M. Akermo, B. Tomas Astrom, Experimental Investigation of Compression Molding of Glass/PP-PP Foam Core Sandwich Components, Journal of Thermoplastic Composite Materials. $12(4)$ (1999) 297-316.

6. M.D. Wakeman, C.D. Rudd b, T.A. Cain b, R. Brooks b, A.C. Long, Compression moulding of glass and polypropylene composites for optimised macro- and micromechanical properties, Composites Science and Technology. 60 (2000) 1901-1918.

7. K.Krishnaiah, P.Shahabudeen, R. Jeyapaul, Quality management research by considering multi response problems in the Taguchi method - a review, Int J Adv Manuf Technol. 26 (2005)1331-1337.

8. D. Sampaio Correia, C. Vasconcelos Gonçalves, Sebastião Simões da Cunha Jr, V. Antonio Ferraresi, Comparison between genetic algorithms and response surface methodology in GMAW welding optimization, J Mater Proc Technol. 160 (2005) 70-76.

9. D. Aleksendrić, A. Senatore, Optimization of manufacturing process effects on brake friction material wear, J Compos Mater. 46 (2012) 2777-2791.

10. D. Yong, Plant location selection based on fuzzy TOPSIS, Int J Adv Manuf Technol. 28(7-8) (2006) 839-844.

11. P. Narender Singh, K. Raghukandan, B.C. Pai, Optimization by Grey relational analysis of EDM parameters on machining Al-10\%SiCP composites, J Mater Proc Technol. 155 (2004) 1658-1661. 